\title{
ANALISIS RENTABILITAS DAN PENYERAPAN TENAGA KERJA PADA AGROINDUSTRI KERIPIK PAKSENG DI DESA WERASARI KECAMATAN SADANANYA KABUPATEN CIAMIS
}

\author{
ANALYSIS OF PROFITABILITY AND LABOR ABSORPTION IN PAKSENG CRIP \\ AGROINDUSTRY IN WERASARI VILLAGE, SADANANYA DISTRICT, \\ CIAMIS REGENCY
}

\author{
JENI $^{1 *}$, DINI ROCHDIANI ${ }^{2}$, AGUS YUNIAWAN ISYANTO ${ }^{1}$ \\ ${ }^{1}$ Fakultas Pertanian Universitas Galuh Ciamis \\ ${ }^{2}$ Fakultas Pertanian Universitas Padjajaran \\ *E-mail: jenidoank567@gmail.com
}

\begin{abstract}
ABSTRAK
Agroindustri keripik pakseng merupakan industri pengolahan pangan yang menggunakan ubi kayu sebagai bahan baku utamanya. Tujuan dari pengolahan ubi kayu menjadi keripik pakseng ini adalah untuk memberikan nilai tambah dan juga meningkatkan pendapatan sekaligus harga jual pada ubi kayu itu sendiri. Terdapat 14 agriondustri keripik pakseng di Desa Werasari Kecamatan Sadananya Kabupaten Ciamis, sehingga perhitungan biaya dan juga kelayakan usaha perlu untuk diketahui, agar usaha tersebut dapat berkelanajutan dan juga memberikan manfaat ke pada pemilik agroindustri. Maka dari itu peneliti tertarik untuk mengetahui; (1). Besarnya biaya, penerimaan, pendapatan, dan kelayakan atau $R / C$. (2). Rentabilitas dan (3). Jumlah tenaga kerja yang terserap pada agroindustr tersebut. Penelitian ini merupakan studi kasus pada agroindustri keripik pakseng yang ada di Desa Werasari dengan dengan teknik penarikan sampel yaitu sampel jenuh. Dari hasil analisis data yang dilakukan maka dapat di peroleh hasil penelitian sebagai berikut : (1). Biaya total yang di keluarkan sebesar Rp.730.357,75 dengan penerimaan Rp. 916.795,92 dan pendapatan Rp. 186.438,17 sehingga $\mathrm{R} / \mathrm{C}$ yang di peroleh 1,26 . (2). Rentabilitas sebesar $25,53 \%$ dari modal yang digunakan. (3). Jumlah tenaga kerja yang terserap 77 orang atau 1,26\% dari 4.660 usia kerja di Desa Werasari.
\end{abstract}

Kata Kunci: Keripik pakseng, rentabilitas, tenaga kerja

\begin{abstract}
Pakseng chips agroindustry is a food processing industry that uses cassava as its main raw material. The purpose of processing cassava into pakseng chips is to provide added value and also increase income as well as the selling price of cassava itself. There are 14 pakseng chips agriondustry in Werasari Village, Sadananya District, Ciamis Regency, so that the calculation of costs and also the feasibility of the business needs to be known, so that the business can be sustainable and also provide benefits to the owners of the agroindustry. Therefore, researchers are interested in knowing; (1). The amount of fees, receipts, income, and eligibility or $R / C$. (2). Profitability. (3). The number of workers absorbed in the agroindustry. This research is a case study on pakseng chips agroindustry in Werasari Village with a sampling technique that is saturated sample. From the results of data analysis carried out, the following research results can be obtained: (1). The total cost incurred is Rp. 730.357 .75 with a receipt of Rp. 916,795.92 and an income of $R p .186,438.17$ so that the $R / C$ obtained is 1.26. (2). Profitability of $25.53 \%$ of the capital used. (3). The number of workers absorbed is 77 people or $1.26 \%$ of the 4,660 working age in Werasari Village.
\end{abstract}

Kewords: Pakseng chips, profitability, labor 


\section{PENDAHULUAN}

Agroindustri merupakan salah satu subsistem agribisnis yang berfungsi untuk memproses produk-produk hasil pertanian menjadi barang jadi maupun setengah jadi. Agroindustri berperan sebagai penggerak utama dalam pengembangan sektor pertanian, terlebih lagi dimasa depan sektor pertanian akan mejadi sektor andalan dalam pembangunan nasional sehingga peranan agroindustri ini akan sangat besar (Suprapto,2008)
Salah satu agroindustri yang banyak berkembang di Kecamatan Sadananya Kabupaten Ciamis adalah agroindustri keripik pakseng. Keripik pakseng sendiri terbuat dari ubu kayu yang di parut lalu dicetak, setelah itu di kukus dan akhirnya di jemur hingga kering.

Terdapat tiga desa yang merupakan sentra produksi keripik pakseng di Kecamatan Sadananya Kabupaten Ciamis.

Tabel 1. Data Agroindustri Keripik Pakseng di Kecamatan Sadananya Tahun 2020

\begin{tabular}{clc}
\hline No & Nama Desa & Unit Usaha (Unit) \\
\hline $\mathbf{1}$ & Werasari & $\mathbf{1 4}$ \\
2 & Tanjungsari & 8 \\
3 & Mangkubumi & 5 \\
\hline & Jumlah & $\mathbf{2 7}$ \\
\hline
\end{tabular}

Sumber: Pemerintah Kecamatan Sadananya, 2020

Agroindustri keripik pakseng merupakan industri pengolahan pangan yang menggunakan ubi kayu sebagai bahan baku utamanya, sehingga agroindustri ini memiliki peranan yang cukup potensial dalam meyerap produksi ubi kayu di Kabupaten Ciamis, khususnya di Desa Werasari Kecamatan Sadananya.

$$
\text { Rata - rata petani ubi kayu hanya }
$$
sebatas menanam, kemudian panen lalu dijual dalam bentuk ubi mentah yang harganya relatif rendah, sehingga pendapatan para petani kurang maksimal. Maka industri pengolahan ubi kayu sangat diperlukan untuk meningkatkan pendapatan para petani, yaitu dengan cara diolah menjadi keripik pakseng yang memiliki nilai ekonomis yang tinggi.

Desa Werasai dipilih sebagai lokasi penelitian dengan pertibangan bahwa Desa Werasari merupakan desa dengan jumlah agroindustri keripik pakseng terbanyak di Kecamatan Sadananya.

Setiap tahapan produksi pada agroindustri keripik pakseng menggunakan biaya yang beragam baik itu biaya untuk penyediaan sarana produksi, peralatan dan juga tenaga kerja. Sehingga perhitungan biaya sangat penting untuk dilakukan agar agroindustri keripik pakseng di Desa 
Werasari mampu mengalokasikan biaya usahanya dengan tepat agar tercapainya pendapatan uasaha yang optimal.

Selain itu dengan adanya agroindustri keripik pakseng ini di harapkan mampu menjadi sumber mata pencaharian untuk maksyarakat Desa Werasari dan juga dapat berdampak positif terhadap perekonomian desa dan nasional.

Sehingga dalam penelitian ini peneliti ingin mengetahui besarnya biaya yang dikeluarkan oleh agroindustri keripik pakseng, penerimaan dan juga pendapatan yang di peroleh, serta besarnya persentase rentabilitas dan juga besarnya tenaga kerja yang terserap oleh agroindustri keripik pakseng.

\section{METODE PENELITIAN}

\section{Jenis Penelitian}

Penelitian pada agroindustri keripik pakseng ini merupakan penelitian kualitatif, dengan studi kasus yaitu agroindustri keripik pakseng yang ada di Desa Werasari. Penelitian studi kasus adalah metode penelitian yang dapat digunakan pada individu maupun kelompok sosial yang terjadi dalam kehidupan nyata dalam jangka waktu tertentu (Aziz, 2003).

\section{Teknik Pengumpulan Data}

Ada dua jenis data yang digunakan untuk penelitian ini, pertama data primer, berasal dari pengusaha keripik pakseng di Desa Werasari dengan menggunakan teknik wawancara. Kedua data sekunder, didapatkan dari intansi-intansi pemerintahan yaitu Dinas Pertanian \& Ketahanan Pangan Kabupaten Ciamis, pemerintah Kecamatan Sadananya dan pemerintah Desa Werasari, seta dari studi literature pada penelitian - penelitian terdahulu.

\section{Teknik Penarikan Sampel}

Desa Werasari Kecamatan Sadananya Kabupaten Ciamis diambil secara purposive sampling atau sengaja, dikarenakan Desa Werasari merupakan lokasi dengan jumlah industri keripik pakseng terbanyak di Kecamatan Sadananya.

Dalam penelitian ini diambil secara sampel jenuh terhadap 14 agroindustri keripik pakseng di Desa Werasari Kecamatan Sadananya Kabupaten Ciamis. Teknik sampel jenuh digunakan apabila seluruh responden dilokasi penelitian diambil seluruhnya sebagai sampel, tujuannya adalah agar hasil penelitian yang di peroleh lebih akurat sesuai dengan fakta dan kondisi di lapangan (Sugiyono,2016). 


\section{Rancangan Analisis Data}

Dalam penelitian ini untuk memperoleh hasil penelitian maka di gunakan rumus - rumus perhitungan berikut ini:

Pertama, untuk menghitung besarnya biaya yang dikeluarkan oleh industri keripik pakseng maka digunakan rumus ( Suratiyah, 2015 ):

Total Cost $(T C)=T F C+T V C$

Dimana:

TFC $=$ Total Fixed Cost (Biaya Tetap Total)

TVC = Total Variable Cost (Biaya

Variabel Total)

Kedua, untuk menghitung total penerimaan pada industri keripik pakseng maka rumus yang digunakan adalah ( Suratiyah,2015 ):

Total Revenue $(T R)=\mathrm{Y} \times \mathrm{Py}$

Dimana:

$$
\begin{aligned}
& \mathrm{Y}=\text { Jumlah Produksi } \\
& \text { Py = Harga }
\end{aligned}
$$

Ketiga, rumus yang digunakan untuk mencari besarnya pendapatan pada industri keripik pakseng dihitung dengan rumus ( Suratiyah, 2015 ):

Pendapatan $=\mathrm{TR}-\mathrm{TC}$

Dimana:

$\mathrm{TR}=$ Total Revenue $($ Penerimaan Total $)$

$\mathrm{TC}=$ Total Cost (Biaya Total)
Keempat, untuk menetukan layak tidaknya industri keripik pakseng untuk terus di usahakan maka digunakan rumus $R / C$ berikut ini ( Suratiyah, 2015 ) :

$$
R / C=\frac{\text { Penerimaan Total }}{\text { Biaya Total }}
$$

Dimana:

- Apabilah nilai $R / C>1$, maka usaha tersebut menguntungkan.

- Apabila nilai $R / C=1$, usaha tersebut tidak mendapatkan keuntungan atau pun kerugian.

- Apabila nilai $R / C<1$, maka usaha tersebut mengalami kerugian.

Kelima, untuk menghitung seberapa besar rentabilitas pada industri keripik pakseng maka perhitungannya menggunakan rumus berikut ini (Riyanto, $2010)$ :

Rentabilitas $(\mathrm{R})=\frac{\text { Laba }(\mathrm{L})}{\operatorname{Modal}(\mathrm{M})} \mathrm{X} 100 \%$

Keenam, untuk menghitung persentase tenaga kerja yang terserap pada industry keripik pakseng maka digunakan rumus berikut ini ( Suratiyah, 2015):

$$
\mathrm{TK}=\frac{\text { Jumlah Tenaga Kerja }}{\text { Jumlah Angkatan Kerja Desa }} \times 100 \%
$$

\section{HASIL DAN PEMBAHASAN}

\section{Umur Pengusaha Keripik Pakseng}

Umur pengusaha agroindustri keripik pakseng di Desa Werasari berkisar antara 22 sampai 60 tahun, dimana usia tersebut 
masih tergoling usia produktif. Daniel (2002), berpendapat masyarakat usia produktif berkisar antara 15 - 64 tahun yang dimana usia tersebut masih produktif dalam bekerja.

\section{Pengalam Berusaha}

Pengalaman berusaha pemilik agroindustri keripik pakseng di desa werasari bervariasi, berkisar antara 0,5 samapai 2,4 tahun.

\section{Tabel 2. Pengalaman Berusaha Pengusaha Agroindustri Keripik Pakseng}

\begin{tabular}{cccc}
\hline No & $\begin{array}{c}\text { Pengalaman Berusaha } \\
\text { (tahun) }\end{array}$ & Jumlah (orang) & Persentase (\%) \\
\hline 1 & $\leq 1$ & 2 & 14,29 \\
2 & $1-2$ & 10 & 71,43 \\
3 & $\geq 2$ & 2 & 14,29 \\
& Jumlah & $\mathbf{1 4}$ & $\mathbf{1 0 0 , 0 0}$ \\
\hline
\end{tabular}

Tabel 2. menunjukan, bahwa pengalaman pengusaha agroindustri keripik pakseng di Desa Werasari sebagian besar 71,43 persen antara $1-2$ tahun, 14,29 persen lebih dari 2 tahun dan 14,29 persen kurang dari 2 tahun.

\section{Tingkat Pendidikan}

Tingkat pendidikan pengusaha agroindustri keripik pakseng rata-rata adalah lulusan Sekolah Dasar (SD) yaitu 6 pengusaha, Sekolah Menengah Atas (SMA) yaitu 5 pengusaha, sarjana yaitu 2 pengusaha dan tamatan SMP yaitu 1 pengusaha.

\section{Tanggungan Keluarga}

Sebagian besar $(64,29 \%)$ tanggungan keluarga pengusaha agroindustri keripik pakseng di Desa Werasari berkisar antara anatara 2-3 orang sebanyak 9 pengusaha, lebih dari 3 orang sebanyak 4 pengusaha dan kurang dari 2 orang sebanyak 1 pengusaha.

\section{Keripik Pakseng}

Salah satu camilan yang banyak di geamari masyarakat adalah keripik, yang umumnya terbuat dari buah - buahan, sayuran maupun umbi - umbian, yang diolah dengan cara digoreng menggunkan minyak nabati, tetapi ada juga keripik yang di buat hanya melalui tahap penjemuran. Umumnya keripik memiliki rasa asin, manis, gurih dan pedas (Oktaningrum dkk, 2013).

Keripik pakseng merupakan olahan pangan lokal yang terbuat dari ubi kayu sebagai bahan baku utamanya yang di olah dengan cara di keringkan. Proses produksi keripik pakseng ini melalui beberapa tahapan proses produksi yaitu pengupasan, pencucian, pemarutan dan penggombangan ubi kayu. Setelah itu dilanjutkan dengan 
proses pencetakan, pengukusan, cara dioseng (disangrai) atau tanpa penjemuran, penyortiran dan pengemasan. menggunakan minyak.

Kepanjangan dari keripik pakseng sendiri adalah opak oseng karena dalam Biaya Agroindustri keripik pakseng

Penggunaan biaya pada industri proses pematangan dari keripik ini dengan keripik pakseng di Desa Werasari terdiri dari biaya tetap dan biaya variabel.

Tabel 3. Rincian Biaya pada Agroindustri Keripik Pakseng di Desa Werasari

\begin{tabular}{clcc}
\hline No & \multicolumn{1}{c}{ Jenis Biaya } & Jumlah $(\mathbf{R p )}$ & Persentase (\%) \\
\hline 1 & Biaya Tetap & & \\
& a. PBB & 74,28 & 0,01 \\
& b. Penyusutan Alat & $9.570,78$ & 1,31 \\
& c. Bunga Modal Tetap & 96,45 & 0,01 \\
& Biaya Tetap Total & $9.741,51$ & 1,33 \\
\hline \multicolumn{1}{c}{ Jenis Biaya } & Jumlah (Rp) & Persentase (\%) \\
\hline 2 & Biaya Variabel & & \\
& a. Ubi Kayu & $287.500,00$ & 39,36 \\
b. Garam & $6.035,71$ & 0,83 \\
& c. Kayu Bakar & $90.714,29$ & 12,42 \\
d. Listrik & $2.803,57$ & 0,38 \\
e. Bensin & $18.714,29$ & 2,56 \\
f. Pelastik Kemasan & $1.142,14$ & 0,16 \\
g. Tali Rapia & $3.000,00$ & 0,41 \\
h. Tenaga Kerja & $293.571,43$ & 40,20 \\
i. Transportasi & $10.000,00$ & 1,37 \\
j. Bunga Modal Variabel & $7.134,81$ & 0,98 \\
Biaya Variabel Total & $720.616,24$ & 98,67 \\
\hline & Biaya Total & $\mathbf{7 3 0 . 3 5 7 , 7 5}$ & $\mathbf{1 0 0 , 0 0}$ \\
\hline
\end{tabular}

Rata-rata agroindustri keripik pakseng mengeluarkan biaya sebesar $\mathrm{Rp}$. 730.357,75 per produksi, dengan biaya tetap sebesar Rp. 9.741,51 serta biaya variabel Rp. 720.616,24. Tiga komponen biaya variabel terbesar terdiri dari biaya tenaga kerja yaitu 40,20 persen, biaya pembelian bahan baku ubi kayu sebesar
39,36 persen dan biaya kayu bakar 12,42 persen.

\section{Penerimaan}

Dilihat dari volume produksi dan harga jual, maka penerimaan yang di peroleh agroindustri keripik pakseng di Desa Werasari Kecamatan Sadananya Kabupaten Ciamis sebesar Rp. 916.795,92 
per prodiksi, dengan harga produk $\mathrm{Rp}$. $19.214,29$ dan volume produksi 47,71 kg.

Tabel 4. Penerimaan Agroindustri Keripik Pakseng di Desa Werasari

\begin{tabular}{clc}
\hline No & \multicolumn{1}{c}{ Uraian } & Jumlah \\
\hline 1 & $\begin{array}{l}\text { Volume } \\
\text { Produksi (kg) }\end{array}$ & 47,71 \\
2 & $\begin{array}{l}\text { Harga Produk } \\
(\mathrm{Rp} / \mathrm{kg})\end{array}$ & $19.214,29$ \\
3 & $\begin{array}{l}\text { Penerimaan } \\
\text { (Rp) }\end{array}$ & $916.795,92$ \\
\hline
\end{tabular}

\section{Total Pendapatan}

Agroindustri keripik pakseng di Desa

Werasari rata-rata memperoleh pendapatan sebesar Rp. 186.438,17, dengan penerimaan sebesar Rp.916.795,92 dengan dikurangi biaya total $730.357,75$.

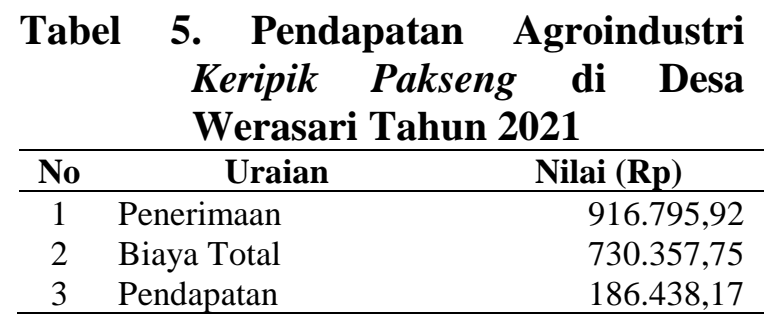

$R / C$

Penerimaan agroindustri keripik pakseng yaitu Rp. 916.795,92 dan biaya total Rp. $730.357,75$, sehingga nilai $R / C$ pada agroindustri keripik pakseng di Desa Werasari sebesar 1,26, sehingga usaha tersebut layak di usahakan karena nilai $R / C$-nya lebih dari satu.

\section{Rentabilitas}

Hasil analisis yang dilakukan terhadap agroindustri keripik pakseng di Desa Werasari menunjukan bahwa ratarata keuntungan yang diperoleh sebesar Rp. 186.438,17 dengan rata-rata modal sebesar Rp. 730.357,75 maka dapat di peroleh rentabilitas sebesar $25,53 \%$.

$$
\begin{gathered}
\mathrm{R}=\frac{\text { Laba }(\text { Pendapatan })}{\text { Modal }} \times 100 \% \\
\mathrm{R}=\frac{186.438,17}{730.357,75} \times 100 \\
\mathrm{R}=25,53 \%
\end{gathered}
$$

\section{Penyerapan Tenaga Kerja}

Berdasarkan hasil penelitian yang dilakukan bahwa tenaga kerja pada agroindustri keripik pakseng di Desa Werasari adalah 77 orang dan angkatan kerja yang ada di Desa Werasari sebanyak 4.660 orang.

$$
\begin{aligned}
\mathrm{TK} & =\frac{\text { Jumlah tenaga kerja }}{\text { Jumlah angkatan kerja }} \times 100 \% \\
& =\frac{77}{4.660} \times 100 \% \\
& =1,65 \%
\end{aligned}
$$

Hasil perhitungan menunjukan bahwa penyerapan tenaga kerja agroindustri keripik pakseng di Desa Werasari yaitu 1,65 persen, artinya usaha agroindustri keripik pakseng di desa werasari mampu menyerap tenaga kerja 1,65\% dari 4.660 angkatan kerja di Desa Werasari Kecamatan Sadananya Kabupaten Ciamis. 


\section{KESIMPULAN DAN SARAN}

\section{Kesimpulan}

Berdasarkan uraian latar belakang dan juga hasil penelitian, maka dapat diperoleh kesimpulan sebagai berikut:

1. Biaya yang dikeluarkan pada agroindustri keripik pakseng di Desa Werasari adalah Rp. 730.357,75, penerimaan Rp. 916.795,92, pendapatan Rp. $186.438,17$ dan $R / C$ 1,26 .

2. Besarnya rentabilitas yang di peroleh agroindustri keripik pakseng di Desa Werasari Kecamatan Sadananya Kabupaten Ciamis sebesar 25,53\% dari modal yang di gunakan.

3. Jumlah tenaga kerja yang terserap pada agroindustri keripik pakseng sebanyak 77 tenaga kerja atau $1,65 \%$ dari 4.660 angkatan kerja yang ada di Desa Werasari Kecamatan Sadananya Kabupaten Ciamis.

\section{SARAN}

Dari kesimpulan penelitian, maka peneliti mengajukan beberapa saran sebagai berikut:

pertama, penggunaan biaya produksi pada agroindustri keripik pakseng harus digunakan seefisien mungkin, terutama penggunaan biaya untuk upah tenaga kerja yang dapat disesuaikan dengan kapasitas produksi yang dimiliki serta pembelian bahan baku (ubi kayu) dengan cara mencari bahan baku yang harganya lebih rendah dalam upaya menekan biaya produksi agar pendapatan yang diperoleh dapat meningkat.

Kedua, nilai rentabilitas dan juga penyerapan tenaga kerja yang cukup besar maka usaha tersebut harus di petahankan dan dikembangkan dalam bentuk industri yang lebih besar, agar semakin banyak tenaga kerja yang terserap sehingga dapat mengurangi tingkat pengangguran di Desa Werasari.

\section{DAFTAR PUSTAKA}

Abdul Aziz SR, 2003, Menyusun Rancangan Penelitian Kualitatif dalam Analisis data Penelitian Kualitatif, Jakarta: Raja Grafindo Persada

Daniel, M. 2002. Pengantar Ekonomi Pertanian. PT Bumi Aksara. Jakarta.

\section{Oktaningrum dkk, 2013. Analisis Kelayakan Ekonomis Substitusi Tepung Lokal Pada Pembuatan Keripik Daun Singkong. Balai Pengkajian Teknologi Pertanian Jawa Tengah.}

Riyanto, B. 2010. Dasar-dasar Pembelajaran Perusahaan. BPFE. Yogyakarta.

Sugiyono. 2016. Metode Penelitian Pendidikan Pendekatan Kuantitatif, Kualitatif dan $R \& D$. Bandung: Alfabeta 
Jurnal Ilmiah Mahasiswa AGROINFO GALUH

Volume 8, Nomor 3, September 2021 : 882-900

Suprapto. 2008. Karakteristik Penerapan dan Pengembangan Agroindustri Hasil Pertanian di Indonesia. Universitas Mercu Buana. Jakarta.
Suratiyah, Ken. 2015. Ilmu Usahatan edisi revisi. Jakarta : Penebar Swadaya. $156 \mathrm{Hal}$. 